\title{
Accessibility of the voicing distinction for learning phonological rules
}

\author{
ALICE F. HEALY \\ Yale University, New Haven, Connecticut 06520 \\ and Haskins Laboratories, New Haven, Connecticut 06510 \\ and \\ ANDREA G. LEVITT \\ Wellesley College, Wellesley, Massachusetts 02181 \\ and Haskins Laboratories, New Haven, Connecticut 06510
}

\begin{abstract}
In three experiments a series of nonsense syllables ending in consonants was presented to adult subjects who had to discover or learn a rule classifying the syllables into two groups. The rule was based either on the voicing of the final consonants or on an arbitrary division of them. Subjects performed better with the voicing than with the arbitrary rule only when there was a straightforward relationship between the voicing rule and the plural formation rule in English or, more generally, when voicing assimilation with an added consonant was involved and attention was focused on the sound and articulation of the syllables. We conclude that the voicing distinction is not ordinarily accessible and that individuals easily learn and use phonological rules involving voicing assimilation because of articulatory constraints on the production of consonant clusters.
\end{abstract}

In order to describe the sounds of the English language, linguists have adopted various systems of distinctive features (see, for example, Jakobson, Fant, \& Halle, 1963). One such distinctive feature corresponds to the presence or absence of voicing. Voiced consonants, such as $/ b, d, g, v, z /$, involve vibrations of the vocal cords, whereas voiceless consonants, such as $/ p, t, k, f, s /$, do not involve such vibrations. There is no doubt that speakers of English hear the consonants within each of these two sets as similar. An analysis of the confusions resulting when subjects listen to consonant-vowel syllables embedded in white noise and identify them (for example, Miller \& Nicely, 1955) reveals that confusions occur largely within voicing category. In fact, not only do the perceptual confusions of consonants reflect the voicing distinction, but also confusion errors in short-term memory reflect the voicing distinction, even when the to-be-remembered letters are presented visually (see, for example, Hintzman, 1967; Wickelgren, 1966). Furthermore, estimates of the similarity between

This research was supported in part by NICHD Grant HD01994 and BRS Grant RR05596 to Haskins Laboratories and NSF Grant BNS77-00077 to Yale University. The authors are deeply grateful to Rick Arons for his help with the design, conduct, and analyses of Experiment 3 and his helpful comments on an earlier version of this manuscript, to Loretta Polka for her help with the design, conduct, and analyses of Experiments 1 and 2, to Bruno Repp and Guy Carden for their helpful comments about this research, and to Robert Crowder for his useful comments on an earlier version of this manuscript. Requests for reprints should be sent to Alice F. Healy, Department of Psychology, Yale University, Box 11A Yale Station, New Haven, Connecticut 06520. various consonant sounds compared in pairs are relatively large when the sounds agree in voicing (Greenberg \& Jenkins, 1964). These results demonstrate that when considered in pairs, consonants in the same voicing category are deemed similar; however, the question remains whether subjects can abstract the voicing distinction across such pairs. In other words, despite the clear effects on behavior of the voicing distinction, the voicing distinction per se may not be accessible for use in learning and memory tasks (cf. LaRiviere, Winitz, Reeds, \& Herriman, 1974). Do adult speakers of English without formal training in linguistics know that $/ \mathrm{b}, \mathrm{d}$, $\mathrm{g}, \mathrm{v}, \mathrm{z} /$ fall within one class of consonants and /p, $t, k$, $\mathrm{f}, \mathrm{s} /$ fall within another, even if they do not know the labels for these classes?

At first glance, the answer to this question seems obvious, since a number of phonological rules make reference to the voicing distinction. For example, one aspect of the rule for forming the plural of English nouns ${ }^{1}$ involves voicing assimilation: The voicing of the final sibilant $/ \mathrm{s} /$ or $/ \mathrm{z} /$ representing the plural morpheme must be the same as that of the immediately preceding segment for stems ending in $/ p, t, k, f, b, d, g, v /$. Thus, the sound of the plural morpheme will be $/ \mathrm{s} /$ for stems ending in $/ p, t, k, f /$ and will be $/ z /$ for stems ending in $/ b, d, g, v /$. One might argue that if individuals know this rule, they must know the distinction between voiced and voiceless consonants. Such an argument seems implied by the "feature" hypothesis of English pluralization discussed by Derwing and Baker (1977). On the basis of this line of reasoning, one would answer the question 
about the accessibility of the voicing distinction affirmatively not only for adults, but also for children 4-7 years old, since even young children have demonstrated the ability to use this plural formation rule productively (Berko, 1958). However, it could also be argued that use of this phonological rule does not require knowledge of the voicing distinction because the rule follows from phonetic or articulatory constraints on the production of consonant clusters" (see, for example, the "phonotactic" rules discussed by Derwing \& Baker, 1977). It is impossible for an individual to pronounce $|z|$ following $/ \mathrm{p}, \mathrm{t}, \mathrm{k}, \mathrm{f} / \mathrm{in}$ a single syllable. For that reason, whether the voicing distinction is accessible is not only an open question, but it is also a very interesting one, since it should illuminate how individuals learn and use the phonological rules involving voicing assimilation.

The aim of the present study was to determine how accessible the distinctive feature voicing is to adult speakers of English. Two paradigms developed by Healy and Levitt (1978) to study the accessibility of syntactic constructs were used in the present investigation to explore the accessibility of the voicing distinction. The first paradigm involved a recognition memory task that allowed us to determine how readily subjects could discover a rule based on the voicing distinction in their attempts to learn a list of nonsense syllables for a subsequent memory test. The second paradigm involved a more conventional concept formation task that allowed us to determine the extent to which subjects could learn by example a rule based on voicing. In both paradigms the rule based on the voicing distinction was compared with an arbitrary rule based on a division of the consonants into two sets, each of which contained both voiced and voiceless members: $b, d, k, f$ in one set and $\mathrm{p}, \mathrm{t}, \mathrm{g}, \mathrm{v}$ in the other. Also, in both paradigms, nonsense syllables ending in consonants were employed as stimuli, and both rules, like the plural formation rule, made reference to the final consonant in the syllables: Syllables ending in one set of consonants were followed by one terminal symbol (for example, s), and syllables ending in the other set of consonants were followed by a second terminal symbol (for example, z). The terminal symbols employed were varied so that they were either distinguishable on the basis of voicing (as in $\mathrm{s}$ and $\mathrm{z}$ ) or were not distinguishable on the basis of voicing (as in ! and ?).

\section{EXPERIMENT 1}

The recognition memory paradigm was employed in Experiment 1. In this experiment subjects studied a series of nonsense syllables, which were presented visually. In the "sz" condition, half of these syllables were followed by the letter $s$ and the other half by the letter $\mathrm{z}$; in the "??" condition, the symbols ! and ? were used instead. At the time of test, the subjects were shown the syllables without their terminal symbols and were asked to indicate for each syllable whether it had been terminated by $s$ or $z$ (or ! or ?) at the time of study. The rule determining the assignment of the terminal symbol was based either on the voicing of the final consonants (the "voicing" conditions) or on the arbitrary division of the final consonants (the "arbitrary" conditions). If the voicing distinction is accessible, subjects in the voicing conditions should perform better than those in the arbitrary conditions. If, on the other hand, subjects can easily discover a rule based on voicing only if it involves voicing assimilation of final consonants, then subjects in the voicing $\mathrm{sz}$ condition should perform better than subjects in each of the other conditions.

\section{Method}

Subjects. Sixty young men and women participated in this experiment. The first 20 subjects were Yale undergraduates who participated for course credit. The remaining 40 subjects were individuals who responded to advertisements posted on the Yale University campus and were paid $\$ 1.25$ for their participation. All subjects were native speakers of English who had had no formal training in linguistics. The subjects were divided into four groups of 15 : voicing sz, voicing !?, arbitrary sz, and arbitrary !?. The assignment of subjects to the four groups was determined by time of arrival for testing according to a fixed rotation of conditions.

Design and Materials. Sixty-four different nonsense syllables were employed as stimuli. The nonsense syllables ended in one of eight consonants, $b, d, g, p, t, k, f, v$, and began with one of eight vowel pairs, ae, ai, au, oe, oi, ou, aa, oo (e.g., aeb, aid). Each of the 64 syllables followed by a terminal character (see below) was typed in the center of four $3 \times 5$ in. cards. Four decks of cards were constructed for use during the study phase of the experiment, one for each of the four conditions. Each deck included all 64 syllables. The terminal characters for two of the four decks (voicing sz and arbitrary $\mathrm{sz}$ ) were $\mathrm{s}$ and $\mathrm{z}$, and for the other two decks (voicing !? and arbitrary !?) they were $!$ and ?. In the decks used for the voicing conditions, the character $s$ or ! followed all syllables ending in the voiceless consonants $p, t, k$, and $f$, and the character $z$ or ? followed all syllables ending in the voiced consonants $b, d, g$, and $v$. In the decks used for the arbitrary conditions, the character $s$ or ! followed all syllables ending in the consonants $p, t, g$, and $v$, and the character $\mathrm{z}$ or ? followed all syllables ending in the consonants $b, d, k$, and $f$. The experimenter thoroughly shuffled the deck of cards before handing it to a given subject, so that the order of the syllables in a given deck varied across subjects.

Four typewritten lists of syllables were constructed for the recognition memory test, one list for each of the four conditions. Each syllable on the two lists used in the sz conditions was followed by the pair of responses written as $(s / z)$, whereas each syllable on the two lists used in the !? conditions was followed by (!/?). Each of the four lists included all 64 syllables; only the order of the syllables varied across lists. In each list, the order of syllables was pseudorandom with the constraints that each 16 -syllable block include two syllables with each consonant and that the order of correct answers ( $s$ or $z$, or ! or ?) be the same for subjects in the voicing and arbitrary conditions.

Procedure. Subjects were tested individually in a single session that lasted approximately $15 \mathrm{~min}$. Each subject was given $5 \mathrm{~min}$ to study one of the four decks of cards (timed by the experimenter with a stop clock) and was warned when the first $2.5 \mathrm{~min}$ had elapsed. Subjects were in no way restricted in their method of studying the syllables, except that they were told to 
pronounce each syllable aloud as a single syllable when they read it. They were allowed to sort the syllables into piles, and they were allowed to look at a given syllable any number of times. The subjects were not encouraged to use any particular strategy in studying the syllables. They were, however, given written instructions describing exactly what their task would be during the recognition memory test. The instructions for the sz conditions were the following: "You will be presented with a stack of cards. On each card is a nonsense syllable which ends in either $s$ or $z$. You are to study these nonsense syllables for five minutes. Pronounce each nonsense syllable aloud as a single syllable when you read it; say it loud enough so that the experimenter can hear you. At the end of five minutes you will be given a sheet of paper which includes each of the nonsense syllables on the cards with the final letter $s$ or $z$ replaced by $(s / z)$. Your task will be to recall for each nonsense syllable whether $s$ or $z$ was at the end of that syllable when it appeared on the card. You are to indicate your response by circling one of the two letters $s$ or $z$ at the end of a given nonsense syllable on the sheet of paper. Before you respond to a given syllable, you are to pronounce it aloud." The instructions for the !? conditions were identical, except that the letters $s$ and $z$ were replaced by the symbols ! and ?, respectively.

After studying the syllables on the cards, the subjects were reminded of their task on the recognition memory test. The subjects were then given the appropriate test list of syllables. They responded to each syllable by pronouncing it aloud and then circling one of the two terminal symbols (s or z, or ! or ?), depending on which symbol they thought occurred with the syllable when it appeared on the card. Subjects were required to respond to every nonsense syllable; they were not allowed to leave blanks. Subjects were given as much time as they needed to complete the recognition memory test.

\section{Results}

The results are summarized in Table 1 in terms of mean percentages of errors on the recognition test as a function of condition. Subjects in the voicing sz group made fewer errors than subjects in the remaining three groups. An analysis of variance performed on these data revealed a significant effect of rule type (voicing or arbitrary) $[\mathrm{F}(1,56)=16.9, \mathrm{MSe}=251.2, \mathrm{p}<.001]$, as well as a significant effect of terminal symbols (sz or !?) $[\mathrm{F}(1,56)=5.5, \mathrm{MSe}=251.2, \mathrm{p}=.021]$, but the interaction of these two factors was not significant $[\mathrm{F}(1,56)=1.3, \mathrm{MSe}=251.2, \mathrm{p}=.251]$.

Planned analyses of variance conducted on each pair of terminal symbols separately yielded a significant effect of rule type for the sz pair of endings $[F(1,28)=$ $18.9, \mathrm{MSe}=184.2, \mathrm{p}<.001]$ but not for the !? pair of endings $[\mathrm{F}(1,28)=3.4, \mathrm{MSe}=318.3, \mathrm{p}=.071]$. Although the effect of rule type was not significant for !? by the standard two-tailed test, it was by a one-tailed test, so

Table 1

Mean Percentage of Errors in Experiment 1 as a Function of Condition

\begin{tabular}{ccc} 
& \multicolumn{2}{c}{ Terminal Symbols } \\
\cline { 3 - 3 } Rule & $\mathrm{sz}$ & $! ?$ \\
\hline Voicing & 10.0 & 24.4 \\
Arbitrary & 31.6 & 36.5 \\
\hline
\end{tabular}

the results would appear somewhat ambiguous for !? from this analysis alone. However, two further analyses indicated that !? did in fact show a smaller effect of rule type than sz. First, planned analyses conducted on each rule type separately yielded a significant effect of terminal symbols for the voicing rule $[F(1,28)=6.7$, $\mathrm{MSe}=230.6, \mathrm{p}=.014]$ but not for the arbitrary rule $[F(1,28)<1]$. Second, an analysis of the number of subjects who made no errors showed that six subjects made no errors in the voicing $\$ z$ group, but only one subject made no errors in the arbitrary sz group. In contrast, for both the voicing!? and the arbitrary !? groups, two subjects made no errors.

\section{Discussion}

A large advantage was found for the voicing over the arbitrary conditions for the sz pair of endings. In contrast, a smaller difference was found between performance levels in the voicing and arbitrary conditions for the !? pair of endings. These findings suggest that subjects can discover a rule based on voicing more easily if the rule involves voicing assimilation than if no assimilation is involved. The most straightforward explanation of these results seems to be based on the fact that voicing assimilation follows from articulatory constraints: Subjects know, for example, that ps is an acceptable final consonant cluster but not $\mathrm{pz}$, simply because they are unable to pronounce $/ \mathrm{pz} /$ at the end of a single syllable. However, an alternative explanation for the results of this experiment is available. Possibly, subjects perform better in the voicing sz condition than in the other three conditions because of the overt similarity to the plural formation rule in English. Subjects can determine the correct answers in the voicing sz condition merely by treating the terminal symbol as the plural morpheme and equating the letter $s$ with the phoneme $\mid s /$ and the letter $z$ with the phoneme $/ z /$.

\section{EXPERIMENT 2}

In order to distinguish between the two explanations proposed above for the results of Experiment 1, a new pair of terminal symbols was selected for examination in Experiment 2: $\mathrm{f}$ and $\mathrm{v}$. These two letters, like $\mathrm{s}$ and $\mathrm{z}$, are distinguishable on the basis of voicing, but unlike $s$ and $z$, their relationship to the sounds representing the plural morpheme in English is not so straightforward, and, in fact, they do not occur following stop consonants in final consonant clusters in English. In addition, $s$ and $z$ were employed in this experiment for comparison, as well as a third pair of symbols, $m$ and $n$. The third pair was selected to replace the symbols ! and ? used in Experiment 1, because like ! and ?, $\mathrm{m}$ and $\mathrm{n}$ are not distinguishable on the basis of voicing, but unlike $!$ and ?, $\mathrm{m}$ and $\mathrm{n}$ are letters and thus permit a comparison of symbol pairs under conditions as analogous as possible. In addition to this change in terminal symbol 
pairs, Experiment 2 involved a change in paradigm. A concept formation task, rather than the recognition memory procedure, was employed, in order to enable us to determine the generality of the findings in Experiment 1 . The concept formation procedure is a more standard experimental technique and has been used by other investigators to study phonological rules. ${ }^{3}$

In this experiment, as in Experiment 1, a series of nonsense syllables was presented visually to subjects. Unlike Experiment 1, only stop consonants were employed in the syllables, since $f$ and $v$ were used as terminal letters in some conditions. The syllables were shown successively in a fixed order. For each syllable, the subjects had to choose the appropriate terminal letter, which was assigned according to the rule based on voicing of the final consonants or the rule based on the arbitrary grouping of final consonants. Subjects were provided immediate feedback after responding to each syllable. Half the subjects in each group were asked to pronounce the syllables aloud with their endings both at the time of responding and after feedback was provided, and the other half were given no explicit instructions to pronounce the syllables aloud. Subjects performed this task in the guise of learning a rule for gender formation in an artificial language, in which one of a pair of terminal letters was used with masculine words and the other with feminine words.

If the voicing distinction is accessible under these conditions, subjects learning the voicing rule should perform better than those learning the arbitrary rule. If, on the other hand, subjects can easily learn a rule based on voicing only if it involves voicing assimilation, the subjects learning the voicing rule with the terminal letter pairs $\mathrm{sZ}$ and $\mathrm{fv}$ should perform better than subjects in each of the other groups. However, if subjects can easily learn a rule involving voicing assimilation only when they are attending to the sound and articulation of the syllables, then subjects in the voicing $s z$ and $\mathrm{fv}$ conditions who are asked to pronounce the syllables aloud should perform better than those who are not so instructed. Alternatively, if subjects can easily learn a voicing rule only if its relationship to the plural formation rule in English is straightforward, then subjects learning the voicing rule with the terminal letter pair sz should perform better than subjects in all the remaining conditions.

\section{Method}

Subjects. Forty-eight male and female Yale undergraduates participated for course credit. All subjects were native speakers of English who had had no formal training in linguistics. The subjects were divided into six groups of eight: voicing sz, voicing $f v$, voicing $m n$, arbitrary $s z$, arbitrary $f v$, and arbitrary $m n$. Each group of eight subjects was further subdivided into two subgroups of four: aloud and silent. The assignment of subjects to groups and subgroups was determined by time of arrival for testing according to a fixed rotation of groups and subgroups.

Apparatus. An Adds 980 terminal, including a typewriter keyboard and a CRT screen and controlled by a PDP-11/45 computer operating under a timesharing system, was used to display the stimuli and receive the subjects' responses.

Design and Materials. Sixty different nonsense syllables were employed as stimuli; they were similar to those used in Experiment 1 , except that six consonants were employed, b, $d, g, p$, $t, k$, and 10 vowel pairs, ae, ai, au, oe, oi, ou, aa, oo, eu, ie. Two lists of syllables were constructed, one for the voicing conditions and one for the arbitrary conditions. Each list included all 60 syllables; only the order varied across lists. In each list the order of the syllables was pseudorandom with the constraints that each 12 -syllable block include 2 syllables with each consonant and that the sequence of correct responses (the correct terminal letters) be the same in the voicing and arbitrary conditions.

Procedure. Each subject was tested individually in a single session lasting approximately $15 \mathrm{~min}$. In each condition, the subject saw at the center top of the display screen the 60 syllables from the appropriate list, one at a time in the prescribed order. The subject was to respond to each syllable by typing at the end of the syllable one of the two terminal letters for the condition, depending on whether the syllable was "masculine" or "feminine" (see below). After the subject responded, the computer supplied immediate feedback below the display of the syllable and the response letter in the form of the statement, "Correct/Wrong, the answer is:__," where the blank was filled by the syllable with its appropriate terminal letter. When the subject was ready for the next trial, he or she was then to press the key "new line," and the screen was cleared and the next syllable appeared on the screen. Syllable presentation was thus subject paced. In the $s z$ conditions, half the syllables were followed by $s$ and half by $z$; in the f $v$ conditions, the syllables were followed by either $f$ or $v$; and in the $m n$ conditions, the syllables were followed by either $m$ or $n$. In the voicing conditions all syllables ending in one of the voiceless consonants $p$, $t$, or $k$ were matched with one of the terminal letters $s, f$, or $m$, and all syllables ending in one of the voiced consonants $b, d$, or $\mathrm{g}$ were matched with one of the corresponding terminal letters $\mathrm{z}$, $v$, or $n$. In the arbitrary conditions the syllables were divided into those ending in $\mathrm{p}, \mathrm{t}$, or $\mathrm{g}$ and those ending in $\mathrm{b}, \mathrm{d}$, or $\mathrm{k}$.

Subjects in the aloud subconditions were explicitly told to pronounce aloud each syllable with its ending as a complete word both at the time of responding and after feedback was given. Subjects in the silent subconditions received no such instructions.

The subjects were instructed that the nonsense syllables they would see represented root words in an artificial language and that gender in the language was denoted by word endings. Half the subjects in each subcondition were told that in the artificial language masculine words ended in $s$ (or $f$ or $m$, depending on the condition) and feminine words ended in $z$ (or $v$ or $n$, depending on the condition). For the remaining half of the subjects, the instructions concerning gender were reversed, so that feminine words were said to end in $s, f$, or $m$ and masculine words in $z$, $\mathrm{v}$, or $\mathrm{n}$. This manipulation insured that the terminal letter was not confounded with gender. The subjects were asked to determine whether each syllable was masculine or feminine and, thus, which member of the terminal letter pair was appropriate for the syllable.

Subjects were told that in the beginning they would have to guess which syllables were masculine and which were feminine, but as the session progressed, they should be able to learn by example the rule that determined gender in the artificial language.

\section{Results}

The results are summarized in Table 2 in terms of mean percentages of errors on the concept formation task as a function of condition and subcondition. Although an advantage for the voicing rule over the 
Table 2

Mean Percentage of Errors in Experiment 2 as a Function of Condition and Subcondition

\begin{tabular}{|c|c|c|c|c|c|c|}
\hline \multirow{3}{*}{$\begin{array}{l}\text { Subcon- } \\
\text { dition }\end{array}$} & \multicolumn{6}{|c|}{ Terminal Letter Pair } \\
\hline & \multicolumn{2}{|c|}{ sz } & \multicolumn{2}{|c|}{$\mathrm{fv}$} & \multicolumn{2}{|c|}{$\mathrm{mn}$} \\
\hline & V & A & $\mathbf{V}$ & A & $\mathbf{V}$ & $\mathbf{A}$ \\
\hline $\begin{array}{l}\text { Aloud } \\
\text { Silent }\end{array}$ & $\begin{array}{l}21.3 \\
29.6\end{array}$ & $\begin{array}{l}49.2 \\
42.9\end{array}$ & $\begin{array}{l}39.6 \\
44.6\end{array}$ & $\begin{array}{l}35.4 \\
37.1\end{array}$ & $\begin{array}{l}40.0 \\
37.1\end{array}$ & $\begin{array}{l}35.8 \\
47.5\end{array}$ \\
\hline Mean & 25.4 & 46.0 & 42.1 & 36.2 & 38.5 & 41.7 \\
\hline
\end{tabular}

Note $-V=$ voicing; $A=$ arbitrary.

arbitrary rule was found for the sz pair of endings, no difference between performance on the two rules was found for the fv or mn ending pairs. In fact, there was a small advantage for the arbitrary rule over the voicing rule for the $\mathrm{fv}$ pair of endings. Neither the main effect of rule type (voicing or arbitrary) $[\mathrm{F}(1,36)=2.0$, $\mathrm{MSe}=1,066.7, \mathrm{p}=.162]$ nor the main effect of terminal letter pair (sz or fv or $\mathrm{mn}$ ) $[\mathrm{F}(2,36)<1]$ was significant, but the interaction of the two factors was significant $[F(2,36)=3.4, \mathrm{MSe}=1,066.7, \mathrm{p}=.044]$. Planned analyses of variance conducted on each pair of endings separately yielded a significant effect of rule type for the sz pair $[F(1,12)=9.1, \mathrm{MSe}=939.0, \mathrm{p}=.011]$ but not for either the fv pair $[F(1,12)<1]$ or the $m n$ pair $[F(1,12)<1]$.

The factor of subcondition (aloud vs. silent) was not significant as a main effect $[F(1,36)<1]$ and did not enter into any significant interactions.

Learning was evidenced by improvement in performance across the five 12-trial blocks. The main effect of blocks was significant $[\mathrm{F}(4,144)=12.9, \mathrm{MSe}=205.4$, $\mathrm{p}<.001]$. However, no differences in the extent of learning as a function of condition were evident. None of the interactions involving the factor of blocks was significant. The differences among conditions therefore emerged within the first block of 12 trials.

\section{Discussion}

No difference was found between levels of performance in the voicing and arbitrary conditions for the terminal letter pairs $\mathrm{mn}$ and $\mathrm{fv}$. This finding, in accord with that for !? in Experiment 1, provides further support for the hypothesis that the voicing distinction is not accessible for use in memory and learning tasks. In contrast, but in agreement with Experiment 1, an advantage was found for the voicing over the arbitrary conditions with the sz pair of endings. Because of the different pattern of results for the $s z$ and fv pairs, these results do not support the hypothesis that subjects can easily learn a rule based on voicing only if it involves voicing assimilation, since voicing assimilation applies for $\mathrm{fv}$ as well as sz. Instead, these results are consistent with the hypothesis that subjects can easily learn a voicing rule only if its relationship to the plural formation rule in English is straightforward.
Perhaps subjects did not easily learn the rule based on voicing assimilation with the $f v$ endings because $f$ and $v$ do not follow stop consonants in final consonant clusters in English. For this reason, subjects working with the $\mathrm{fv}$ endings might have resisted attending to the sound and/or articulation of the syllables. Furthermore, although there were no significant differences between the aloud and silent subconditions, subjects in both the voicing $f v$ and voicing sz conditions made fewer errors in the aloud than in the silent subconditions. In order to examine more thoroughly the importance of sound and articulation, we turned to the auditory, rather than the visual, modality in Experiment 3. The use of the auditory modality should encourage attention to the sound and articulation of the syllables rather than to their visual features and therefore might lead to better performance with the fv endings. Also, the auditory modality is of interest in this context, since it is the modality used by children when learning a language.

\section{EXPERIMENT 3}

Experiment 3 was essentially a replication of Experiment 2 except for two changes: (1) The stimuli were presented auditorily rather than visually, and (2) the terminal letters a and $o$, which are also not distinguishable on the basis of voicing, were used instead of $m$ and $n$. The letter pairs were changed in order to make it easier for the subjects to pronounce the syllables with their endings. The initial aural presentation of the stimuli without the endings in this experiment allowed us to make sure that the subjects would clearly hear the distinction between the voiced and voiceless consonants.

If the change to the auditory modality does draw attention away from the irrelevant visual properties of the syllables, thereby forcing the subjects to rely on the sound and articulation of the syllables, the subjects learning the voicing rule with the fv endings should perform better than those learning the arbitrary rule with the $f v$ endings. If, on the other hand, the change to the auditory modality does not have the intended effects, the results of this study should essentially replicate those of Experiment 2.

Once again subjects in each group were divided into two subgroups: those required to pronounce aloud the syllables with their endings (aloud) and those not given any explicit instructions to do so (silent). We expected to find an advantage for the aloud subgroup in the voicing sZ and voicing fv conditions, if subjects can learn a rule based on voicing assimilation only when they are attending to the sound and articulation of the syllables.

\section{Method}

Subjects. Seventy-two male and female Yale undergraduates were employed; 65 received course credit, and the remaining 7 participated purely on a volunteer basis. All subjects were native speakers of English who had had no formal training in linguistics. As in Experiment 2, the subjects were divided into six equal groups. The groups were analogous to those used in 
Experiment 2 except that the mn groups were replaced by ao groups. Also as in Experiment 2, each group of subjects was further subdivided into aloud and silent subgroups. The assignment of subjects to groups and subgroups was determined by time of arrival for testing according to a fixed rotation of groups and subgroups.

Apparatus. The stimuli (syllables, names of the terminal letters, and the phrase "the correct answer is") were recorded on an Ampex AG 500 tape recorder in a soundproof room by a female native speaker of English (A.G.L.), who clearly articulated the syllables and released the final stop consonants so that the distinction between the voiced and voiceless consonants was obvious. These stimuli were digitized using the Haskins Laboratories pulse code modulation system (Cooper \& Mattingly, Note 1). Subsequently, the stimuli were edited for starting point and end point, by adjusting the duration of the silent periods at the start and end, to insure that the presentation times for all syllables were equal $(640 \mathrm{msec})$, as were those for the names of all the terminal letters $(660 \mathrm{msec})$. The stimuli were reconverted into analog form and recorded on both channels of a twochannel Crown 800 tape recorder. The use of the pulse code modulation system insured that all instances of a given stimulus on the tapes were identical.

The stimuli were transmitted to the subject binaurally through a pair of Telephonics earphones (Model TDH-39). The stimulus tapes were played with a TEAC A-3300S tape recorder at a comfortable listening level.

Design and Materials. Sixty different nonsense syllables were employed as stimuli; they were analogous to those used in Experiment 2. As in Experiment 2, six consonants were employed, $/ b, \mathrm{~d}, \mathrm{~g}, \mathrm{p}, \mathrm{t}, \mathrm{k} /$, and 10 vowels, $/ \mathrm{i}, \mathrm{I}, \mathrm{e}, \supset, \Lambda, \mathrm{u}, \mathrm{o}, \epsilon, \boldsymbol{\infty}, \mathrm{a} / . \mathrm{Six}$ tapes were constructed, one for each of the six conditions. Each tape included 60 trials. A trial consisted of the following sequence of events: (1) the presentation of a vowel-consonant syllable, (2) a 6-sec silent interval, (3) the statement, "the correct answer is," (4) a $590-\mathrm{msec}$ silent interval, (5) the name of the correct terminal letter, (6) a $3-\mathrm{sec}$ silent intertrial interval. At the end of every block of 12 syllables was a 7 sec silent interval in addition to the 3-sec silent intertrial interval. The order of presentation of the syllables on the tapes corresponded exactly to the order used in Experiment 2, with the vowels $/ \mathbf{a}, \mathrm{e}, \supset, \Lambda, \mathrm{i}, \epsilon, \mathrm{I}, \mathrm{u}, \mathrm{a}, \mathrm{o} /$ replacing the vowel pairs ae, ai, au, eu, ie, oe, oi, ou, aa, oo, respectively. The tapes for the $\mathrm{sz}, \mathrm{fv}$, and ao conditions were identical except that the terminal letters $s$ and $z$ on the $s z$ tapes were replaced by $f$ and $v$ on the fr tapes and $a$ and $o$ on the ao tapes.

Procedure. As in Experiment 2, each subject was tested individually in a single session lasting approximately $25 \mathrm{~min}$. Each subject participated in one of the six conditions, defined by the rule to be learned (voicing or arbitrary) and the terminal letter pair (sz, fv, or ao), and in one of two subgroups (aloud or silent). The subjects were to respond to each nonsense syllable by circling one of the two terminal letters beside the trial number on an answer sheet. The subjects were given $6 \mathrm{sec}$ to make each response. As in Experiment 2, subjects in the aloud subconditions, but not those in the silent subconditions, were told to pronounce aloud each syllable with its ending as a complete word both at the time of responding and after feedback was given in the form of the name of the correct terminal letter.

The instructions given to the subjects were analogous to those used in Experiment 2, except that the subjects were warned to be prompt in making their responses because the timing was fixed in advance and could not be changed.

\section{Results}

The results are summarized in Table 3 in terms of mean percentages of errors on the concept formation task as a function of condition and subcondition. An
Table 3

Mean Percentage of Errors in Experiment 3 as a Function of Condition and Subcondition

\begin{tabular}{|c|c|c|c|c|c|c|}
\hline \multirow{3}{*}{$\begin{array}{l}\text { Subcon- } \\
\text { dition }\end{array}$} & \multicolumn{6}{|c|}{ Terminal Letter Pair } \\
\hline & \multicolumn{2}{|c|}{$\mathbf{s z}$} & \multicolumn{2}{|c|}{ fv } & \multicolumn{2}{|c|}{ ao } \\
\hline & $\mathbf{V}$ & A & V & $\mathbf{A}$ & V & A \\
\hline $\begin{array}{l}\text { Aloud } \\
\text { Silent }\end{array}$ & $\begin{array}{l}18.9 \\
37.8\end{array}$ & $\begin{array}{l}42.2 \\
41.9\end{array}$ & $\begin{array}{l}24.4 \\
25.3\end{array}$ & $\begin{array}{l}42.5 \\
32.8\end{array}$ & $\begin{array}{l}45.3 \\
32.5\end{array}$ & $\begin{array}{l}44.4 \\
36.1\end{array}$ \\
\hline Mean & 28.3 & 42,1 & 24.9 & 37.6 & 38.9 & 40.3 \\
\hline
\end{tabular}

Note $-V=$ voicing; $A=$ arbitrary.

advantage for the voicing rule over the arbitrary rule was found for the sz and the fv pairs of endings, but no difference between the two rules was found for the ao pair. The main effect of rule type (voicing or arbitrary) was significant $[\mathrm{F}(1,60)=8.7, \mathrm{MSe}=892.8, \mathrm{p}=.005]$, but the main effect of terminal letter pair (sz, fv, or ao) $[\mathrm{F}(2,60)=2.3, \mathrm{MSe}=892.8, \mathrm{p}=.103]$ and the interaction of rule type and terminal letter pair $[\mathrm{F}(2,60)=$ $1.6, \mathrm{MSe}=892.8, \mathrm{p}=.211 \mathrm{]}$ were not significant. Planned analyses of variance conducted on each pair of endings separately yielded a significant effect of rule type for the sz pair $[F(1,20)=6.6, \mathrm{MSe}=863.1, \mathrm{p}=.018]$ and for the $\mathrm{fv}$ pair $[\mathrm{F}(1,20)=5.1, \mathrm{MSe}=954.9, \mathrm{p}=.033]$, but not for the ao pair $[F(1,20)<1]$. Additional planned analyses conducted on each rule type separately yielded an effect of terminal symbol that just missed significance for the voicing rule $[F(2,30)=3.0$, $\mathrm{MSe}=1,056.1, \mathrm{p}=.062]$, but the effect did not approach significance for the arbitrary rule $[F(2,30)<1]$.

The subcondition manipulation did prove to be important in this experiment. Specifically, subjects in the voicing sz and voicing $\mathrm{fv}$ conditions performed somewhat better in the aloud subconditions than in the silent subconditions, but a difference in the opposite direction was found for subjects in the four remaining conditions. The three-way interaction of terminal letter pair, subcondition, and rule type was not significant in the overall analysis $[\mathrm{F}(2,60)=1.2, \mathrm{MSe}=892.8, \mathrm{p}=$ .309]; however, the two-way interaction of terminal letter pair and subcondition was significant in the overall analysis $[\mathrm{F}(2,60)=3.5, \mathrm{MSe}=892.8, \mathrm{p}=.036]$. Further, the analyses conducted on the two rule types separately revealed a significant interaction of terminal letter pair and subcondition for the voicing rule $[F(2,30)=3.6$, $\mathrm{MSe}=1,056.1, \mathrm{p}=.039$ ] but not for the arbitrary rule $[\mathrm{F}(2,30)<1]$.

An examination of the pattern of errors as a function of final consonant suggests that subjects may have had a natural tendency to use the voicing rule in the arbitrary aloud subcondition: The greatest number of errors in that subcondition occurred for syllables ending in $\mathrm{g}$ or $k$, the only two of the six final consonants that violated the voicing rule. This pattern of errors is depicted in Table 4 , which provides mean error percentages as a 
Table 4

Mean Percentage of Errors in Experiment 3 as a Function of Rule Type, Subcondition, and Final Consonant

\begin{tabular}{ccccc}
\hline & \multicolumn{4}{c}{ Rule Type } \\
\cline { 2 - 5 } & \multicolumn{2}{c}{ Voicing } & \multicolumn{2}{c}{ Arbitrary } \\
\cline { 2 - 3 } \cline { 4 - 5 } $\begin{array}{c}\text { Final } \\
\text { Consonant }\end{array}$ & Aloud & Silent & Aloud & Silent \\
\hline B & 25.0 & 33.3 & 47.2 & 42.2 \\
D & 28.3 & 32.8 & 33.3 & 28.3 \\
G & 30.6 & 30.0 & 51.7 & 33.3 \\
P & 33.3 & 23.3 & 35.0 & 40.0 \\
T & 32.8 & 32.2 & 35.0 & 37.2 \\
K & 27.2 & 39.4 & 56.1 & 40.6 \\
\hline
\end{tabular}

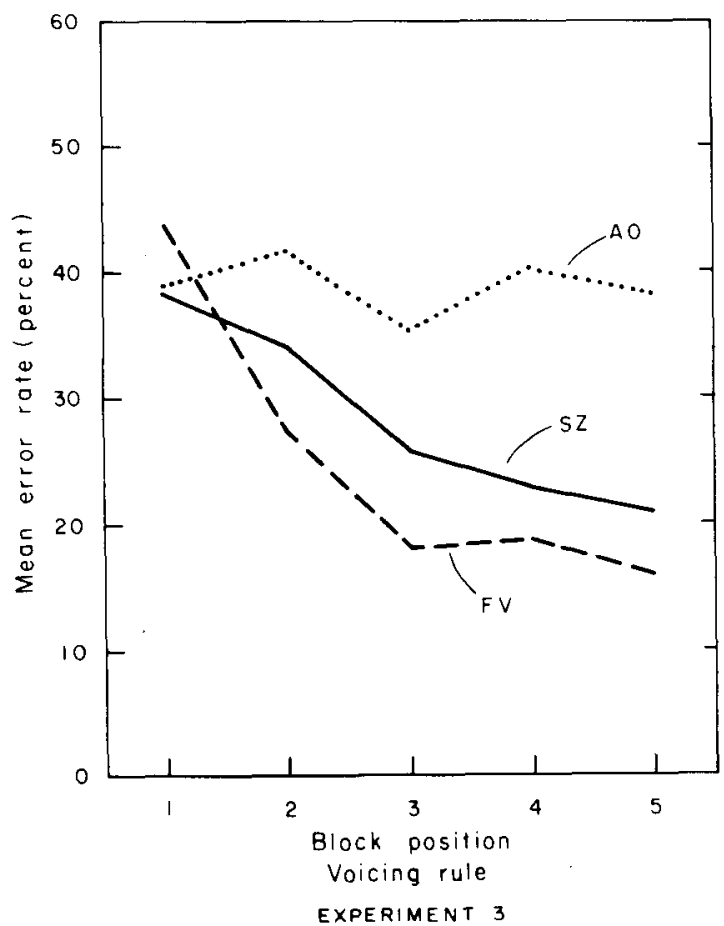

Figure 1. Mean percentage of errors in the voicing conditions of Experiment 3 as a function of terminal letter pair and block position.

function of rule type, subcondition, and final consonant. In the overall analysis of variance, the main effect of final consonant was significant $[\mathrm{F}(5,300)=3.6, \mathrm{MSe}=$ $252.0, \mathrm{p}=.004]$, as was the interaction of rule type and final consonant $[F(5,300)=2.8, M S e=252.0, p=.018]$ and the second-order interaction of rule type, subcondition, and final consonant $[\mathrm{F}(5,300)=4.1, \mathrm{MSe}=252.0$, $p=.001]$. These results illustrate the salience of the voicing rule in the aloud subconditions.

Learning was evident across the five 12-trial blocks $[F(4,240)=15.7, \mathrm{MSe}=173.3, \mathrm{p}<.001]$. Although none of the interactions involving blocks were significant in the overall analysis, the interaction of terminal letter pair and blocks was significant in the analysis of the voicing rule $[F(8,120)=2.2, \mathrm{MSe}=179.4, \mathrm{p}=.030]$, reflecting the greater learning of the voicing rule in the $\mathrm{SZ}$ and $\mathrm{fv}$ conditions than in the ao condition. This interaction is depicted in Figure 1, which provides mean error percentages as a function of trial block position and terminal letter pair for the voicing rule. The corresponding interaction was not significant for the arbitrary rule $[F(8,120)<1]$, although the main effect of blocks was significant for both the arbitrary rule $[\mathrm{F}(4,120)=7.6, \mathrm{MSe}=167.4, \mathrm{p}<.001]$ and the voicing rule $[\mathrm{F}(4,120)=8.5, \mathrm{MSe}=179.4, \mathrm{p}<.001]$, reflecting the fact that some learning took place for both rules. In the analysis conducted on each of the terminal letter pairs separately, including both voicing and arbitrary rules, the main effect of blocks was significant for the sz pair $[\mathrm{F}(4,80)=5.3, \mathrm{MSe}=177.3, \mathrm{p}=.001]$ and the fv pair $[F(4,80)=12.4, \mathrm{MSe}=162.6, \mathrm{p}<.001]$, but not for the ao pair $[F(4,80)=1.9$, MSe $=180.1$, $\mathrm{p}=.122]$, providing further support for greater learning in the sz and $f v$ conditions than in the ao condition.

\section{Discussion}

No difference was found between performance on learning the voicing and arbitrary rules for the terminal letter pair ao. This finding is consistent with the findings for the terminal symbol pairs!? in Experiment 1 and $\mathrm{mn}$ in Experiment 2. Since the distinction between the final voiced and voiceless stop consonants was made clear by the initial aural presentation of the syllables, this result gives support to the hypothesis that the voicing distinction is not accessible for use in learning tasks. As in Experiments 1 and 2, an advantage was found for the voicing over the arbitrary conditions with the sz pair of endings. Furthermore, unlike Experiment 2, an advantage. was also found in this experiment for the voicing over the arbitrary conditions with the fv pair of endings. This finding suggests that use of the auditory modality does in fact draw attention away from the irrelevant visual properties toward the sound and articulation of the syllables, and that under such conditions subjects can easily learn a rule involving voicing assimilation. The importance of articulation of the syllables for learning the voicing assimilation rule was further supported by the fact that there was some advantage for the aloud over the silent subconditions in the voicing conditions when the terminal letter pair was sz or fv (but not when it was ao and not in the arbitrary conditions).

A paired associate learning experiment by Jenkins, Foss, and Greenberg (1968) also demonstrated the importance of articulation in learning a rule based on distinctive features. Subjects in this experiment learned a list of six pairs of consonant-vowel syllables. For the control group of subjects, the response terms were randomly paired with the stimulus terms. For the experimental groups of subjects, the stimuli and responses were identical in terms of all features except voicing 
(for example, pa was paired with ba). The several experimental groups differed in the instructions given to them directing their attention to the type of relationship between the stimuli in a pair. For example, one experimental group of subjects was told to attend to "what your mouth is doing as you say the syllables" (Jenkins et al., 1968, p. 202). This group performed better than the other experimental groups, who were not directed to the articulation of the syllables, and these groups in turn performed better than the control group.

\section{SUMMARY AND CONCLUSIONS}

We have found that subjects can discover or learn a rule based on the distinctive feature voicing more easily than a rule based on an arbitrary division of consonants only when the relationship between the voicing rule and the plural formation rule is straightforward or, more generally, when the voicing rule involves voicing assimilation and attention is paid to the sound and articulation of the stimuli. These results suggest that the voicing distinction is not ordinarily accessible to subjects for use in memory and learning tasks. This conclusion should not be taken to imply that the voicing distinction does not play some role in perception and memory. In fact, to the contrary, as reviewed in the introduction, there is considerable evidence that the voicing distinction does have important effects on memory and perception. However, the conclusion reached here concerning the inaccessibility of the voicing distinction is inconsistent with the claim that learning and use of various phonological rules in English such as the plural formation rule depend on the analysis of voicing as a distinctive feature (cf., the "feature" hypothesis of Derwing \& Baker, 1977). We propose instead that individuals easily learn and use phonological rules involving voicing assimilation because of articulatory constraints. Subjects know that syllables ending in $/ \mathrm{p}, \mathrm{t}, \mathrm{k} /$ are followed by $/ \mathrm{s} /$ and syllables ending in $/ \mathrm{b}, \mathrm{d}, \mathrm{g} /$ are followed by $/ \mathrm{z} /$ simply because they are unable to pronounce syllables ending in consonant clusters $/ \mathrm{pz}, \mathrm{tz}, \mathrm{kz} /$. This study vividly illustrates that the form in which a linguist most clearly specifies a given rule need not be the form in which the rule is learned and used by speakers of the language.

The fact that the voicing feature is not ordinarily accessible for use in learning and memory does not necessarily imply that other distinctive features are also inaccessible. In fact, in a categorization paradigm, in which each of a small set of consonant-vowel syllables differing only in their initial consonants was placed into one of two categories, LaRiviere et al.(1974) found that the voicing distinctive feature was not accessible but other distinctive features (for example, the strident feature) were. It would be of interest to determine whether such a difference in the accessibility of features is also found with the procedures developed in the present study.

\section{REFERENCE NOTES}

1. Cooper, F. S., \& Mattingly, 1. G. Computer-controlled PCM system for investigation of dichotic speech perception. Haskins Laboratories Status Report on Speech Research (SR-17/18), 1969, pp. 17-21.

2. Dinnsen, D. A. Phonological rules and phonetic explanation. Paper reproduced by the Indiana University Linguistics Club, 1978

3. Cena, R. M. When is a phonological generalization psychologically real? Paper reproduced by the Indiana University Linguistics Club, 1978.

\section{REFERENCES}

Berko, J. The child's learning of English morphology. Word, 1958, 14, 150-177.

Derwing, B. L., \& Baker, W. J. The psychological basis for morphological rules. In J. Macnamara (Ed.), Language learning and thought. New York: Academic Press, 1977.

Greenberg, J. H., \& Jenkins, J. J. Studies in the psychological correlates of the sound system of American English. Word, $1964,20,157-177$.

Healy, A. F., \& LevitT, A. G. The relative accessibility of semantic and deep-structure syntactic concepts. Memory \& Cognition, 1978, 6, 518-526.

Hintzman, D. L. Articulatory coding in short-term memory. Journal of Verbal Learning and Verbal Behavior, 1967, 6, 312 . 316 .

Jakobson, R., Fant, C. G. M., \& Halle, M. Preliminaries to speech analysis: The distinctive features and their correlates. Cambridge, Mass: M.I.T. Press, 1963.

Jenkins, J. J., Foss, D. J., \& Greenberg, J. H. Phonological distinctive features as cues in learning. Journal of Experimental Psychology, 1968, 77, 200-205.

LaRiviere, C., Winitz, H., Reeds, J., \& Herriman, E. The conceptual reality of selected distinctive features. Journal of Speech and Hearing Research, 1974, 17, 122-133.

Miller, G. A., \& Nicely, P. E. An analysis of perceptual confusions among some English consonants. Journal of the Acoustical Society of America, 1955, 27, 338-352.

WiCKelgren, W. A. Distinctive features and errors in shortterm memory for English consonants. Journal of the Acoustical Society of America, 1966, 39, 388-398.

\section{NOTES}

1. The plural formation rule in English is equivalent to the rule for forming possessives of English nouns and the thirdperson singular of the present tense of English verbs. We shall refer to all these rules collectively as the "plural formation rule."

2. Progressive voice assimilation, in which the second phoneme in a consonant cluster is made to agree in voicing with the first phoneme, is the solution used in English to the articulatory constraints. Dinnsen (Note 2) points out that other languages employ another solution to the articulatory constraints: regressive voice assimilation, in which the first phoneme is made to agree in voicing with the second phoneme.

3. Cena (Note 3) reviewed a set of studies on vowel alternation rules and discussed the relative merits of the experimental techniques employed in those studies. He concluded that the concept formation technique was preferable to some of the others employed because of its built-in control for response bias, a control also incorporated in the recognition memory procedure used in Experiment 1.

(Received for publication October 8, 1979; accepted October $31,1979$. ) 